\title{
UNIVERSIDADE SOLIDÁRIA E DIFERENÇAS CULTURAIS - UM GRANDE DESAFIO ${ }^{1}$
}

\section{Sílvia Helena de Oliveira Piazentino*}

\begin{abstract}
"O mais importante e bonito no mundo é isto: que as pessoas não estão sempre iguais, ainda não foram terminadas - mas que elas vão sempre mudando"
\end{abstract}

Guimarães Rosa

O ano de 1999, último ano de minha graduação, foi um ano especial, rico em experiências que foram desenvolvidas ao cumprir as exigências do $4^{\underline{0}}$ ano do curso de Pedagogia. Uma delas foi a participação no Programa Universidade Solidária.

No final de 1998, houve a inscrição dos universitários que pretendiam participar do Programa Universidade Solidária, um dos inúmeros programas desenvolvidos pelo Comunidade Solidária, cujo objetivo é o de mobilizar universitários para conhecer melhor a realidade do país e participar de um exercício de responsabilidade social, no qual os estudantes divulgam informações e promovem atividades para a melhoria das condições de saúde, educação e organização das comunidades, trabalhando com lideranças locais que possam atuar como agentes multiplicadores. É, portanto, uma forma de aproximarmos o conhecimento acadêmico da população que não tem acesso a ele.

\footnotetext{
* Pedagoga formada pela Faculdade de Educação da PUC-CAMPINAS em 1999, atualmente mestranda do Programa de Pós-Graduação em Educação da mesma instituição, bolsista da CAPES e orientanda da Profa. Dra Olinda Maria Noronha.
} 
À Pontifícia Universidade Católica de Campinas - PUCCampinas, universidade da qual fui uma das representantes, coube desenvolver trabalhos no município de Mâncio Lima, no Estado do Acre, enviando anteriormente um professor para fazer o diagnóstico das demandas municipais.

Mâncio Lima, município desde 1976, situa-se a vinte quilômetros de Cruzeiro do Sul, segunda maior cidade do Estado do Acre. Anteriormente colônia de seringueiros, contava, na época da nossa visita, com dez mil habitantes. É uma cidade pobre, mas sem a miséria com que nos defrontamos diariamente em cidades maiores como, por exemplo, Campinas. É composta por várias comunidades que procuram se autogerir, evitando, assim, o êxodo para a região central do município.

As prioridades diagnosticadas anteriormente pelo professor enviado envolviam necessidades amparadas por dez cursos, a saber: Jornalismo, Psicologia, Educação Física, Engenharia Sanitária, Nutrição, Enfermagem, Pedagogia, Medicina, Odontologia e Biblioteconomia.

O professor coordenador, responsável pelo grupo, e os universitários de cada área iniciaram a elaboração de planos de ação, a seleção de material didático de apoio e a confecção de recursos necessários ${ }^{3}$.

O treinamento, durante o mês de dezembro de 1998, envolveu todos os cursos. A cada dia, através da contribuição de um docente dos cursos, ocorria o esclarecimento dos integrantes do grupo sobre as ações possíveis a serem desenvolvidas para atingir o objetivo do Programa Universidade Solidária: levar algumas contribuições para a comunidade e não resolver seus problemas. Além disso, tinha-se a preocupação de aprender também. Por isso, o elemento fundamental a ser desenvolvido - a solidariedade entre os membros do grupo e entre o grupo e a comunidade. Vale a pena ressaltar que a grande diferença entre este programa e o extinto Projeto Rondon, é o seu caráter preventivo e não assistencialista.

Este treinamento foi importante para que cada universitário conhecesse um pouco sobre cada área e para que houvesse o entrosamento do grupo, o qual iria conviver vinte e oito dias distante de seus familiares, com pessoas diferentes, estranhas, num lugar totalmente desconhecido. 
Após o treinamento, entregamos para a Coordenadoria Geral de Extensão (COGEX) - que administra os programas de extensão da PUC-Campinas - o material didático-teórico e material complementar, o qual foi denominado como bagagem técnica. Entregamos também o plano de ação individual na área educacional, contemplando as diretrizes de ação - metodologias e objetivos - além do plano geral, elaborado pelo professor coordenador, auxiliado pelo grupo, baseado nos planos individuais anteriormente citados.

O plano de ação específico da educação compreendia a alfabetização no ensino básico e a alfabetização de jovens e adultos, o ensino especial, as rotinas burocráticas da escola e a utilização de sucata como material didático-pedagógico auxiliar, principalmente madeira, que é abundante na região.

O encontro de todas as universidades envolvidas no Programa Universidade Solidária se deu na Base Aérea de Guarulhos, São Paulo, em 9 de janeiro de 1999. Embarcamos para Manaus e lá fomos instalados no quartel do Centro de Instrução de Guerra na Selva (CIGS) - Comando Militar da Amazônia - para a realização do Estágio de Adaptação Amazônico, o qual nos instruiu sobre a região e como sobreviver às suas condições naturais.

O tempo do estágio foi meticulosamente organizado para que fosse cumprido por completo, incluindo até atividades de lazer e turismo programadas pelo comandante do CIGS. Após o encerramento desta etapa, embarcamos em um avião Hércules C-130, o qual nos levou até Cruzeiro do Sul, onde fomos recebidos pelas autoridades de Mâncio Lima, pela banda militar do 61ํㅡㄹ BIS (Batalhão de Infantaria da Selva) e pelo comandante responsável pelo respectivo batalhão. Ressalta-se que a responsabilidade de locomoção de todas as equipes - por terra, água e ar - é das Forças Armadas, cabendo aos municípios proporcionar acomodação e alimentação aos grupos.

Ficamos alojados no Centro Betânia, de propriedade da Igreja Católica, e tivemos um micro-ônibus designado para nosso transporte durante a estada.

A nossa grande surpresa foram as inúmeras inscrições feitas para os cursos que os "técnicos" da PUC-Campinas iriam ministrar, ampla e erroneamente divulgados pela prefeitura municipal. Só para a 
área de educação tivemos mais de duzentos inscritos. A população achava que seriam ministrados cursos profissionalizantes e, dada as dificuldades vividas por ela, entendemos a grande quantidade de inscrições.

Esta falha de interpretação do Programa Universidade Solidária pelas autoridades locais fez com que todos nós universitários, auxiliados pelo professor coordenador, refizéssemos nossos planos de ação. Para tanto, estabelecemos um cronograma de dois dias, objetivando o reconhecimento da cidade e da comunidade, com reuniões do grupo para reelaboração das atividades e reuniões com os líderes locais para esclarecimentos necessários.

A proposta final elaborada pelas alunas de Pedagogia, em virtude do alto número de inscrições, estabeleceu um dia para trabalharmos com a administração escolar, um dia com a supervisão escolar, três dias com o planejamento educacional e três dias com a alfabetização.

Fixamos os programas em locais estratégicos, no centro e nos bairros, aproveitando todas as oportunidades para nos mantermos informadas.

Com as visitas aos bairros pudemos perceber a precariedade do município com relação ao saneamento básico e sistema de abastecimento de água, o estado precário das unidades escolares e das casas dos moradores. A maioria dos bairros contava com posto de saúde, igreja, escola e local para a integração e lazer da comunidade. Todas as comunidades tinham uma casa de farinha e todos trabalhavam na "farinhada". Todos os bairros tinham o roçado de macaxeira, atrás das casas, sendo esta a única produção agrícola do local, dada a degradação da terra, na qual anteriormente foram cultivados café, feijão e cana-de-açúcar.

O centro da cidade, chamado Vila, concentrava o comércio, correio, igreja matriz, prefeitura, câmara municipal, dentre outros estabelecimentos. Foi o único lugar em que encontramos casas de alvenaria, diferentemente dos bairros, onde as casas são de madeira. Pela cidade de Mâncio Lima passa o rio Japiin (nome de um pássaro nativo) que, ao chegar em Cruzeiro do Sul, recebe o nome de Rio Moa, desembocando no Rio Juruá. Os igarapés - pequenos rios geralmente vadeáveis - são utilizados para a lavagem de roupas e louças. 
Após este breve panorama geográfico da cidade, vamos nos ater aos dados referentes à área educacional. De acordo com o Secretário Municipal de Educação, a rede municipal não era um sistema organizado, poucas escolas tinham um regimento escolar interno, seguindo o regimento estadual. Pouco tempo antes da nossa chegada foi realizado o primeiro concurso público municipal para os cargos educacionais - docentes e não-docentes - sendo aprovadas pessoas com curso de magistério e pessoas que concluíram apenas a $4^{\text {a }}$ série do ensino fundamental. Na zona urbana, os professores tinham a habilitação para o magistério ou haviam concluído a 4" série do ensino fundamental, enquanto na zona rural - conhecida como ribeirinha - os professores, na sua maioria, não tinham concluído a $4^{\mathrm{a}}$ série do ensino fundamental.

A Secretaria Municipal de Educação seguia todas as orientações dadas pela Inspetoria de Ensino Estadual (equivalente às Diretorias de Ensino do Estado de São Paulo). Na rede municipal, o prefeito indicava quem ocuparia os diversos cargos, utilizando como critérios a formação e o partidarismo político. Na rede estadual ocorriam eleições para os cargos de direção, e as disputas eram tão acirradas quanto as disputas políticas. Poucos fizeram ou faziam o curso de pedagogia em Cruzeiro do Sul (faculdade ligada à Universidade Federal do Rio Branco) e, ao longo dos trabalhos, através de observações e diálogos estabelecidos com os participantes das atividades, percebemos ser esse curso superior apenas um "magistério mais elaborado", com grade curricular bem diferente da ministrada no curso de pedagogia da PUC-Campinas, no ano de 1999.

As maiores dificuldades e problemas elencados pelo Secretário Municipal da Educação estavam relacionados à qualificação de pessoal - principalmente com a falta de compromisso e assiduidade - defasagem idade/série dós alunos, repetência, desistência e, conseqüente, evasão escolar.

Outro fato que nos chamou a atenção dizia respeito ao papel do supervisor escolar, que nada mais era que o de um professor coordenador da rede estadual paulista. O trabalho de supervisão, equivalente ao do estado de São Paulo, é realizado no estado do Acre, pelo inspetor de ensino. Levando-se em conta a existência de dois grupos - situação e 
oposição - que se revezam no poder, a cada mudança se altera o responsável pela Inspetoria de Ensino - a qual representa a Secretaria Estadual de Educação - o que afeta a continuidade de qualquer trabalho a ser realizado na região.

O Projeto Brasil Criança Cidadã, coordenado pela primeira-dama do município, atendia cerca de cento e quarenta crianças, entre sete e quatorze anos. Havia uma marcenaria que confeccionava jogos com madeira da região (Marupá) e, como não podiam profissionalizar-se, as crianças não lidavam com as máquinas, exercendo apenas serviços de lixamento e pintura. Além disso, desenvolviam atividades de lazer e esporte, atividades lúdicas e oficinas bem como as de reforço escolar, segundo as informações recebidas pela primeira-dama, as quais não puderam ser confirmadas dado o período de férias escolares.

Iniciamos as atividades relacionadas com administração escolar, suprindo as necessidades do público atendido (total de cinqüenta e três pessoas) que estavam relacionadas às funções do diretor e à organização da secretaria das escolas.

Com o desenvolvimento do encontro foi perceptível a falta de preparo e de capacitação da grande maioria, o que pode explicar a pouca participação dos presentes nas atividades desenvolvidas. No entanto, percebemos nitidamente que todos estavam atentos ao que era tratado. Eram sempre as mesmas pessoas que se manifestavam, questionavam.

O segundo dia de trabalho foi sobre supervisão escolar e o grupo era composto por cinquienta e nove pessoas. A participação foi muito maior e a nossa preocupação foi a de realizar um trabalho utilizando a denominação conhecida por eles. Pediram-nos esclarecimentos quanto aos Parâmetros Curriculares Nacionais (PCNs), o que foi muito interessante já que os tínhamos analisados no curso de Pedagogia da PUC-Campinas.

Nos três dias seguintes, o trabalho foi sobre planejamento. Esclarecemos os conceitos, as diferenças e relações entre planejamento e planos, os vários níveis de planejamento (esmiuçando o Projeto Político Pedagógico), planos de curso e de aula. A cada dia trabalhamos com um número grande de pessoas (noventa e quatro, cinquienta e quatro e setenta e nove respectivamente) e, além dessa dificuldade, tivemos do 
lidar com situações nas quais o partidarismo político se apresentava de forma constrangedora. Atualmente, com o aprofundamento das reflexões realizadas no curso de Mestrado em Educação da PUCCampinas e auxiliada por diversos autores, como Morais, por exemplo, entendemos porque isso ocorria:

Por comodismo ou excessiva (mas inconfessável) limitação, escolhem-se uns poucos dogmas como referenciais e avalia-se tudo em virtude deles. Eis porque denominamos atitudes assim como a ingenuidade do furor crítico, pois, na melhor das hipóteses, isso é ingênuo, e, na pior, é incompetente mesmo (2000, p. 55).

Encerrou-se a primeira semana de trabalho e todas as oportunidades de participação nas atividades desenvolvidas pelos outros universitários foram aproveitadas, conforme o acordo prévio de trabalho estabelecido em conjunto. Interessante observar a integração entre os alunos dos cursos diferentes. Uma integração possível na prática, a qual poderia estender-se ao cotidiano do espaço acadêmico também, transpondo barreiras, socializando experiências, articulando ensino e pesquisa e tantas possibilidades mais.

Iniciamos a última etapa do trabalho previsto e, durante três dias, desenvolvemos conteúdos relacionados ao processo de alfabetização. No primeiro dia trabalhamos com setenta e quatro pessoas, auxiliadas pelo membro da equipe do curso de Educação Física.

Analisamos, primeiramente, a relevância dos jogos e brincadeiras no desenvolvimento das capacidades inerentes ao processo de ensino e aprendizagem como, por exemplo, o conhecimento corporal, a orientação e a organização espacial e temporal, a coordenação visiomotora, o domínio motor, a lateralidade e a interação social, já que "o jogo não é uma atividade isolada de um grupo de pessoas formadas ao acaso: ele reflete experiências, valores da própria comunidade em que estão inseridas" (ALMEIDA, 1990, p. 37)

A seguir, foram desenvolvidas atividades práticas programadas e coordenadas pelo aluno da Faculdade de Educação Física da PUCCampinas, exemplificando de maneira concreta o desenvolvimento dos pré-requisitos descritos anteriormente. 
Foi um momento rico, de trocas culturais, de respeito e de aprendizado intenso. Algumas brincadeiras desenvolvidas normalmente na região Sudeste não são realizadas na região em que estávamos pois, na cultura presente, são atividades que "dão azar".

No período vespertino, objetivando refletir sobre a questão da alfabetização na perspectiva de esclarecimentos e encaminhamentos pedagógicos, utilizamos, como procedimento metodológico, a socialização de experiências dos professores no grande grupo. Em pequenos grupos, fez-se o levantamento dos conceitos, definições e informações que apresentavam sobre alfabetização, finalizando com a projeção de transparências sobre o tema.

Os aspectos levantados e discutidos pelo grupo relacionados com a prática pedagógica foram a organização do ambiente físico, o fator temporal e a relevância dos conteúdos a serem desenvolvidos. A prática pedagógica de alfabetização teve como fundamentação teórica as contribuições de Piaget (teoria do desenvolvimento cognitivo) e Vigotsky (teoria da mediação) e suas implicações no processo de ensino e de aprendizagem.

Tendo a criação e o desenvolvimento de contextos educativos como a base do processo educativo, analisou-se o papel do educador como:

sujeito que se insere no processo educativo de um grupo e interage com os outros sujeitos... a especificidade de sua intervenção educativa consiste em dedicar particular atenção às relações e aos contextos que vão se criando, de modo a contribuir para a explicitação e elaboração dos sentidos (percepção, significado e direção) que os sujeitos em relação constroem e reconstroem" (FLEURI, 2000, p. 80).

Com relação à alfabetização de jovens e adultos, analisamos com o grupo sua dimensão social e política, o componente ético e a cultura, dentro de uma proposta de alfabetização conscientizadora, salientando os procedimentos pedagógicos inerentes à ação educativa proposta por Paulo Freire.

Considerando a nossa formação em pedagogia e a especificidade da educação especial, discutimos aspectos relacionados aos recursos 
não disponibilizados nos programas educacionais regulares (por exemplo, os sistemas especiais de comunicação), a precariedade da formação do educador para que possa elaborar uma ação educativa que corresponda às necessidades educativas especiais, atendendo ao processo de inclusão presente na legislação educacional e nos Parâmetros Curriculares Nacionais.

Dando continuidade aos trabalhos programados para o segundo dia, o grupo foi dividido em três turmas para a realização das oficinas pedagógicas, as quais aconteceram nos períodos da manhã e da tarde.

O objetivo das oficinas pedagógicas foi o de oportunizar situações para a elaboração de recursos didático-pedagógicos que pudessem contribuir para o ensino e aprendizagem.

Em pequenos grupos e com o assessoramento das alunas de Pedagogia da PUC-Campinas, participantes do Programa Universidade Solidária, os grupos confeccionaram recursos pedagógicos - por exemplo, jogos para o ensino de matemática e de português - que atenderiam às suas necessidades, utilizando diversos materiais, inclusive sucata.

As dificuldades apresentadas pelos professores no entendimento da confecção de alguns jogos e sua utilização foi notória, o que nos remete à questão da formação do educador. Segundo Imbernón:

os docentes precisam desenvolver capacidades de aprendizagem... a formação assume um papel que vai além do ensino que pretende uma mera atualização científica, pedagógica e didática e se transforma na possibilidade de criar espaços de participação, reflexão e formação (...) (2000, p. 18).

Ser um profissional da educação implica dominar inúmeras capacidades e habilidades específicas que o tornem competente no seu trabalho, participante na emancipação das pessoas, tornando-as mais livres e menos dependentes dos poderes econômico, político e social.

Encerrar esta fase dos trabalhos com o Projeto Leitura foi relevante principalmente se considerarmos as palavras de Paulo Freire:

a leitura da palavra não é apenas precedida pela leitura do mundo mas por uma certa forma de 'escrevê-lo' ou de 'reescrevê10', quer dizer, de transformá-lo através de nossa prática consciente (1993, p. 20). 
A exposição teórica compreendeu algumas considerações sobre leitura, como exploração de textos diversificados e a sala de aula como espaço estimulador que favoreça o contato dos educandos com certa quantidade e variedade de material escrito; estratégias de leitura (seleção, antecipação, inferência, autocontrole, autocorreção) e extração de informações através do ato de ler, que ativa diversas ações mentais do leitor; ler e aprender a ler como estratégia de ensino utilizada para melhorar a qualidade do processo contínuo de ensino e de aprendizagem; enfoques de interpretação (conteúdo, estrutura e análise do discurso) e o conhecimento do professor das características específicas para a adequada aplicação aos textos utilizados.

As atividades práticas do Projeto Leitura foram desenvolvidas em escolas de três bairros do município (abertas com este intuito, visto que no momento estavam em férias escolares).

As crianças participaram de maneira tímida inicialmente, soltando-se, pouco a pouco, com o desenrolar das atividades, as quais envolveram várias obras da literatura infantil e teatro de fantoches, salientando-se, nesse trabalho, aspectos da higiene corporal e atividades artísticas com diversos materiais.

Este trabalho também foi desenvolvido com a participação dos universitários de diversas áreas de ensino da PUC-Campinas, com contribuições riquíssimas, confirmando assim a necessidade da humildade em reconhecer que nosso saber não é absoluto, total, e que precisamos do coletivo para a reconstrução do conhecimento, ligandoo ao social, fazendo-o ter uma função social, como diz Pedro Demo (1997).

Após o passeio programado pela prefeitura para a Serra do Moa, no pé da Serra do Divisor (divisa do Brasil com o Peru), nos preparamos para o encerramento do Programa Universidade Solidária, o qual aconteceu no único local de lazer da cidade, o Clube Céu. Tivemos que providenciar certificados para os participantes, dada a importância disto para eles. As despedidas foram emocionantes e, apesar de todas as dificuldades encontradas, nos sentimos realizadas. Afinal, muitos questionamentos foram levantados neste período, fazendo com que a população começasse a perceber sua realidade, unindo-se num esforço coletivo para mudanças. Esse processo de conscientização político- 
social é demorado como o processo de aprendizagem que "tem seu tempo, pois passa pela elaboração, interpretação, reconstrução, e não apenas por um procedimento de gravação mecânica" (DEMO, 1997, p. 28)

Podemos concluir, a partir da reflexão sobre essa experiência, que a dificuldade de lidar com as diferenças é enorme.

Neste país, particularmente, elas são inúmeras, abrangendo aspectos sociais, econômicos, culturais..., presentes em todos os contextos e relações sociais. Se esta diversidade, presente no trabalho pedagógico, não for respeitada, o processo de ensino e de aprendizagem se torna vazio, difícil de ser concretizado.

São inúmeras as contradições existentes e todas elas são fundamentais para que nós educadores façamos uma análise reflexiva, nos comprometendo com a opção política que fizermos, como bem diz Paulo Freire (1996).

A partir da vontade dos homens, da organização coletiva em torno de objetivos comuns é que ocorrerá o processo de transformação social. Caso contrário, se nos mantivermos passivos diante da concepção dominante, aceitaremos todos os problemas educacionais como sendo meramente administrativos.

Vale lembrar Castanho quando afirma que "a educação, como processo vivo e dinâmico, cresce na qualidade do serviço que presta, na medida em que vive no dia a dia a íntima e indissociável relação técnica/política" (1996, p. 55), criando condições que favoreçam a participação, não apenas no contexto escolar, mas nos inúmeros contextos que permeiam a nossa vida.

\section{Notas}

1. Esta experiência é parte integrante da monografia elaborada como exigência parcial para a obtenção do título de Licenciado em Pedagogia pela Faculdade de Educação da PUC-CAMPINAS, com o título "Relação família e escola: uma vivência de esperança", sob a orientação da Profa. Eliana Pires da Costa.

2. Membros da equipe: Prof. Bruno Fuser (Jornalismo), Patrícia Capovila (Jornalismo), Andréa F. Martins (Psicologia), Leonardo B. 
Pignata (Educação Física), Daniel G. Carvalho (Engenharia Sanitária), Patrícia Anicézio (Nutrição), Marcela R. Santos (Enfermagem), Onéa S. Arruda (Pedagogia), Juliana B. Cruz (Medicina) e Marinês C. Ribeiro (Biblioteconomia).

\section{Referências}

ALMEIDA, P. N. Educação lúdica: técnicas e jogos pedagógicos. 6.ed., São Paulo: Loyola, 1990.

CASTANHO, M. E. L. M. Os objetivos da educação. In: VEIGA, I. P. A. (Coord.) Repensando a didática. 12.ed. Campinas: Papirus, 1996.

DEMO, Pedro. Conhecimento moderno: sobre ética e intervenção no conhecimento. Petrópolis: Vozes, 1997.

FLEURI, R. M. Multiculturalismo e interculturalismo nos processos educacionais. In: CANDAU, V. M. (Org.). Ensinar e aprender: sujeitos, saberes e pesquisa. Encontro Nacional de Didática e Prática de Ensino (ENDIPE). Rio de Janeiro: DP\&A, 2000.

FREIRE, Paulo. Pedagogia da autonomia: saberes necessários à prática educativa. São Paulo: Paz e Terra, 1996.

A importância do ato de ler: em três artigos que se completam. 28.ed. São Paulo: Cortez, 1993.

IMBERNÓN, F. Formação docente e profissional: formar-se para a mudança e a incerteza. São Paulo: Cortez, 2000.

MORAIS, J. F. R. de. A criticidade como fundamento do humano. In: VEIGA, I. P. A.; CASTANHO, M. E. L. M. (Orgs.). Pedagogia universitária: a aula em foco. Campinas: Papirus, 2000. 